\title{
A Ciência da Lógica de Hegel como Filosofia primeira
}

\section{Hegel's Science of Logic as Prima Philosophy}

\author{
Denis Lerrer Rosenfield ${ }^{1 *}$
}

\section{Resumo}

A Ciência da Lógica é, propriamente falando, uma obra de Filosofia primeira, voltada à interrogação sobre o começo do conhecimento, sobre o ser e suas determinações categoriais. Em linguagem hegeliana, trata-se do ser em seu vir-a-ser, culminando na Ideia, passando pela mediação da Essência. Conhecida por sua dificuldade, a Ciência da Lógica apresenta inusitadas novidades para quem se aventura a lê-la como uma obra de filosofia primeira, que se articula enquanto peça fundadora em relação a todo o sistema hegeliano. A partir de uma indagação sobre as diferentes acepções do começo e, também, sobre a questão de como dizer que algo existe, a atualidade da filosofia hegeliana ganha particular relevância.

Palavras-chave: Hegel, Lógica, Filosofia.

\begin{abstract}
The Science of Logic is, properly speaking, a "Prima" philosophy work, turned on the query concerning the knowledge beginning, the being and its categorical determinations. Departing from the Hegelian languages, one deals with Being in its "fiery" having, as its summit, the Idea, transiting through Essence mediation. Acknowledged by its difficulty, the Science of Logic presents unusual novelties for one who dares reading it - Science of Logic as a "Prima" philosophy work, wich links together, while a fouding piece, with the whole Hegelian system. Departing from a query on the Beginning different acceptances and, as well as, on the question concerning the way how one can say that something exists, the Hegelian philosophy actually gets particular importance. Key words: Hegel. Logic. philosophy

O título da obra, Wissenchaft der Logik, já é revelador do projeto hegeliano. Chama primeiramente atenção o fato de Hegel utilizar o conceito de Wissenchaft para uma obra que trata de filo-
\end{abstract}

\footnotetext{
$1 \quad$ * Professor Títular do Programa de Filosofia da UFRGS, Pesquisador 1A do CNPQ. Email: denisrosenfield@terra.com.br.
} 
sofia primeira. Nesse sentido, o título mais adequado deveria ser o de Filosofia da lógica. Uma resposta possível a essa indagação seria a de que o autor procura guardar o mesmo leque semântico presente em conceitos como o de "saber" (Wissen), que tão importante papel joga em expressões como "Saber absoluto" e "saber puro". Poderíamos mesmo ser tentados a traduzir Wissenschaft por "sabedoria", em consonância com o gênio próprio da língua brasileira. A questão, no entanto, permanece, porque o conceito de Wissenschaft, já na época de Hegel, tinha a conotação de "ciência" no sentido de um corpo rigoroso de proposições voltado para o conhecimento de um setor específico da realidade, embora também fosse de uso corrente a expressão "filosofia natural".

Mais concretamente, porém, pode-se entender o título desta obra como uma resposta ao desafio lançado por Kant, a saber, o de se a metafísica poderia se constituir como ciência. Ora, Kant tem em vista os progressos da física de Newton enquanto paradigma científico, tomando, pois, o conceito de ciência nessa acepção particular. Seu ponto consiste não num corpo de conhecimento que abarcaria um setor particular da realidade, mas no rigor demonstrativo, na forma de sua fundação, na justificativa apresentada de conceitos perfeitamente demonstrados. A resposta de Hegel é, então, oferecida na Ciência da Lógica, à medida que o repto, aceito, reside em provar que a metafísica como ciência é possível. Nessa perspectiva, este livro seria, propriamente dito, um livro de metafísica, de filosofia primeira, voltado para a apresentação das categorias em seu encadeamento lógico, o que lhe conferiria essa acepção particular de lógica, onde a lógica clássica é enfocada sob uma ótica metafísica e pós-kantiana. A proposta propriamente de filosofia primeira já se faz presente no capítulo introdutório desta obra: Die Lehre vom Sein. Womit muß der Anfang der Wissenschaft gemacht werden?, onde a doutrina do ser vem acompanhada da questão relativa ao começo da reflexão filosófica. Uma mesma questão se encontra formulada no capítulo $\S 39$ da Enciclopédia, em que Hegel formula a questão do "ser puro" em termos do conceito de absoluto. 
Na metafísica o pensamento se pensa a si mesmo, o que implica uma reflexão sobre a linguagem, sobre as formas de se dizer o ser enquanto formas mediante as quais a razão apresenta-se a si mesma, na objetividade de seu próprio discurso, sem nenhuma referência externa. O pensamento se diz, assim, ser. Isso implica a dissolução das formas fixas do entendimento em proveito de determinações-de-pensamento que se fazem ao sabor de suas dicções de si, de suas enunciações. O problema do discurso metafísico, ao contrário do discurso científico, consiste em que ele é apoiado apenas em si mesmo, em sua própria forma de sustentação/elaboração, não tendo um objeto externo a si que funcione como ponto de referência ou, mesmo, como critério de verdade. O seu objeto é ele/si mesmo e não algo dado exteriormente a si, que ganharia o contorno da objetividade empírica, o dito objeto dos objetos do mundo.

A Ciência da Lógica é uma obra que trata de categorias. No sentido aristotélico, categorias são modos de inquirir, modos de interpelar a realidade. E, portanto, as categorias são atribuídas ao indivíduo, à substância individual, considerada como algo exterior ao pensamento. Na verdade, a substância não é uma categoria que tenha o mesmo estatuto conceitual das demais, à medida que ela é a base mesma da predicação, o fundamento a partir do qual as outras categorias são atribuídas, tornando possível o conhecimento propriamente dito. Mais precisamente, poderíamos dizer que são formas de pensar que nos dão condições de indagar a realidade, ou seja, são perguntas dirigidas a uma substância tida por substância individual, primeira neste sentido, descortinando uma determinada abordagem da realidade.

A Ciência da Lógica trata essencialmente de categorias que se encadeiam em sua dedução conceitual, uma sendo engendrada pela outra, segundo uma lógica interna e específica. Em alguns momentos, pode-se ter a impressão de que Hegel está falando de algo real, externo ao pensamento, quando, na verdade, ele está apenas seguindo esse encadeamento categorial. Assim, por exemplo, quando ele fala da vida, ele está pensando o conceito de vida na perspectiva da Idéia que se realiza. Não é a mesma 
coisa discorrer sobre a vida e analisar o conceito de vida. Isso porque a Lógica é um livro que trata de categorias e da forma como que elas vão desenvolver-se - uma será deduzida da outra. Nessa perspectiva, Hegel não estaria somente fazendo um Organon no sentido aristotélico, mas um Organon diretamente acoplado a uma filosofia primeira, voltada para a indagação do ser, do começo do saber, e de como atribuir a existência a algo pensado.

Podemos, então, dizer que a pergunta "qual tem de ser o começo da ciência?”, “com o que tem de ser feito o começo da ciência" pode ser vertida para as seguintes questões: $\mathrm{O}$ que é o ser? O que é a existência? Como podemos dizer que algo existe? Na Ciência da Lógica, há o que se pode considerar como uma outra acepção da existência, a existência noética, a existência dos conceitos. Um exemplo consiste na atribuição da existência ao conceito de absoluto ou a Deus na acepção corrente do termo. A referência ao absoluto aparece tanto na Ciência da Lógica quanto na Enciclopédia. Assim, o que Hegel vai fazer consiste em deduzir todas as categorias das categorias anteriores: ser, nada e devir. Mc Taggart irá, sob essa ótica de leitura, propor a distinção entre o real e o existente ${ }^{2}$, de tal maneira que aquilo tido por real será tributário do modo de se conceber a existência. O real pressupõe a sua explicitação categorial, o que implica, na visão hegeliana, a apresentação dos conceitos subjacentes ao conceito de ser, que vai, depois de um longo percurso categorial, realizar-se, se expor no conceito de Idéia.

A Ciência da Lógica pressupõe a Fenomenologia do Espírito. Essa última obra é a ciência da consciência em seu aparecer, tal como ela se faz "consciência de si", "razão", "espírito" e, por último, "Saber absoluto" ou "saber puro". Ou seja, a pergunta "qual tem de ser o começo da ciência?", "com o que tem de ser feito o começo da ciência?", pressupõe que o "começo" do ponto de vista lógico é o resultado de todo um caminho fenomenológico.

MacTaggart A commentary on Hegel's Logic. New York. Russell \& Russel.1964, p. 6-7.

204 - Universidade Católica de Pernambuco 
A questão do começo tal como formulada na Ciência da Lógica é tributária do desenvolvimento fenomenológico da consciência realizando-se e concretizando-se na forma mais elevada do saber, a do Saber absoluto que interiorizou em si os seus momentos fenomenológicos e lógicos. As categorias vieram a desenvolver-se e se apresentar nos diferentes "momentos"3 da "consciência", da "consciência-de-si”, da "razão" e do "espírito". O "saber puro" é a certeza tendo chegado à verdade, ou a certeza que não está mais em face do objeto, mas que o interiorizou e purificou-o. Ela sabe o objeto como ela mesma - ela tem a si mesma como seu objeto - o do saber, que faz a dedução de suas categorias. Portanto, a Lógica é o "Saber absoluto" na articulação de seus conceitos, no vir-a-ser de suas categorias.

O ponto de partida consiste no saber puro, e, portanto, no Saber absoluto. Quando conhecemos através do Saber absoluto, quando sabemos a partir do Saber absoluto, nós não sabemos a partir da oposição entre o subjetivo e o objetivo. A perspectiva do Saber absoluto não é a da consciência, pois ele se encontra para além dela. O saber puro retira, portanto, do "eu" as suas significações limitadas e cotidianas, que realçam a sua posição insuperável em relação ao objeto. Por essa razão, não se pode considerar essa atitude como "subjetiva". O "eu" que Hegel toma frequentemente como objeto de crítica não é o "eu" do Saber absoluto, mas o "eu" da consciência, aquele que se defronta com o fenômeno, aquele que não percorreu ainda o movimento fenomenológico do em-si, do para-si e do em-e-para-si. Contudo, mesmo se o "eu" fosse, de fato, o saber puro ou se a intuição intelectual fosse, de fato, o começo, o problema permaneceria, visto que, na ciência, nós não tratamos apenas com aquilo que estaria presente anteriormente, mas com o ser-aí que o interior tem no saber. O ser-aí do Saber absoluto é o ser-aí que incorporou toda a sua experiência de mundo, do qual ele faz parte. O aparecente a si mesmo é o pro-

Vaz, Henrique de Lima. "Senhor e escravo: uma parábola da filosofia ocidental". In: Síntese, nº 21, janeiro/abril 1981. 
cesso através do qual ele fez o seu percurso de constituição de si. Trata-se dessa forma de existência que configura o modo de ser do saber. "O saber parte do ser-aí", eis a afirmação de Hegel que condensa a problemática mesma da Ciência da Lógica.

O percurso da consciência natural é um percurso que ocorre dentro dela mesma ${ }^{4}$, com o intuito de que possa liberar o Saber absoluto ou, o que é a mesma coisa, o conceito geral da ciência. A consciência só é plenamente se conseguir chegar a ser propriamente uma consciência especulativa, capaz de apresentar as figuras e as determinações-de-pensamento que a fazem ser o que ela é. A Fenomenologia do Espírito consiste na apresentação dessas figuras, enquanto a Ciência da Lógica consiste na exposição dessas determinações-de-pensamento.

O processo da consciência pode ser dito um processo vertical de aprofundamento em si mesma, porém um processo que não parte de uma consciência individual, pré-histórica por assim dizer, mas de uma consciência culturalmente formada, aquela que se apresenta como o resultado do percurso mediante o qual a humanidade vem a se conhecer e a se saber. Ou seja, no momento em que a consciência natural ou individual entra em si mesma, esse ato de entrada é um ato de introdução ao processo de formação cultural já realizado em todo um percurso da ciência, do saber. Esse conservou em si tanto as etapas essenciais de sua constituição como o processo de passagem e de mediação de uma nas outras, segundo o desdobramento da negação e da negação da negação, isto é, o automovimento da negatividade.

Pode-se, portanto, dizer que tanto a Fenomenologia do Espírito quanto a Ciência da Lógica tratam de realidades imateriais, inteligíveis, que não são as do domínio empírico, as relativas ao conhecimento do mundo exterior, mas as que se constituem, propriamente, em objetos metafísicos. Esses objetos metafísicos,

\footnotetext{
4 Bourgeois, Bernard, "Sens et intention de la Phénoménologie de l'Esprit ». In : Hegel. Préface, Introduction de la Phénoménologie de l'Esprit. Paris, Vrin, 1997, p.10. 
no entanto, são objetos elaborados pela própria consciência no exercício do seu pensar, na identidade que lá se estabelece entre pensar e ser, de tal maneira que eles devem preliminarmente passar pelo crivo de um tratamento crítico ${ }^{5}$ desses conceitos e de seu emprego, o que teria, para Hegel, sido levado a cabo por essas suas duas obras maiores.

A especificidade da Lógica reside em sua visão retrospectiva apresentada categorialmente enquanto tal, pois ela parte da culminação da Fenomenologia, procurando, a partir daí, reconstituir os momentos centrais das determinações-de-pensamento. A Ciência da Lógica expõe retrospectivamente e verticalmente o percurso lógico da consciência que se desdobrou e se apresentou em seu movimento figurativo. E, neste movimento figurativo, que é um processo de formação cultural, o ser já se apresentou como a questão central, não apenas por ser ele, filosoficamente, a questão por excelência, desde o poema de Parmênides, mas, também, por estar ele presente no uso que fazemos de qualquer frase e proposição mediante o uso da cópula e.

O saber puro consiste na apresentação das categorias, pressupondo a "suspensão" (Aufhebung), a superação da dualidade entre o subjetivo e o objetivo, graças ao percurso fenomenológico, numa unidade de exteriorização que recupera em si o seu desenvolvimento lógico. A Ciência da Lógica vai, nesse sentido, apresentar as determinações lógicas do seu processo de exteriorização, cuja mediação fenomenológica, baseada na distinção entre o sujeito e o objeto, foi superada. O saber puro parte de um olhar retrospectivo sobre o seu processo de constituição, de modo que a reflexão sobre o ser pressupõe um começo sui generis, o do começo na acepção do Saber absoluto. O começo da Lógica parte do conceito de ser, tal como está presente no Saber absoluto. A Ciência da Lógica começa onde o Saber absoluto termina e, portanto, vai colocar uma outra noção de ser.

Cf. Longuenesse, Béatrice. Hegel e la critique de la métaphysique. Paris, Vrin, 1981.

Ano $13 \cdot$ n. $1 \cdot$ jan./jun. $2013-207$ 
Logo, a questão do começo se imbrica à do "fundamento", entendido em sua acepção categorial, tal como apresentada no segundo tomo da Ciência da Lógica, o da "Doutrina da Essência". Isto é, o fundamento consiste no processo mediante o qual as figuras se dissolvem e se engendram. Ele é produto do processo da "reflexão", mediante o qual uma determinação é posta pela outra. Na "Doutrina da Essência", ocorre uma dissolução de uma categoria por outra, dando lugar a uma categoria superior, produto desse processo de engendramento recíproco. Trata-se de uma dissolução criadora, que engendra, produz, e, não simplesmente elimina. Consequentemente, o ser não tem conteúdo positivo, sendo, por assim dizer, armado por seu processo de dissolução criadora, constituindo-se num começo propriamente reflexivo da filosofia. Sob essa ótica, o ser é resultado, culminação de um processo lógico a partir dessa dissolução, que teve sua face fenomenológica e se apresentará, agora, logicamente, categorialmente.

Devemos, dessa maneira, convir que o "progredir", o “avançar" se dá no interior mesmo da Ciência da Lógica, constituindo-se numa volta ao fundamento, ao originário assim concebido. O progredir não pode ser associado a uma sucessão temporal, como aquela que significamos cotidianamente quando falamos do progresso de uma sociedade ou das sociedades em geral. Para Hegel, o critério é essencialmente lógico, entendido como uma volta ao fundamento em sua dupla acepção de zugrundegehen abismamento (ir ao abismo), de dissolver - e de zu Grunde gehen - ir ao fundamento, enquanto resultado desse processo. Em consequência, é também necessário, por outro lado, considerar como resultado o que faz o movimento de retorno ao seu fundamento. Sob esta ótica, o primeiro é o fundamento e o último, algo deduzido, pois, enquanto se parte do primeiro, chega-se ao último como fundamento. O progresso a partir daquilo que faz o começo é, além disso, uma determinação ulterior desse começo, de modo que esta se encontra novamente no fundamento de tudo o que segue e do qual surge. $\mathrm{O}$ começo da filosofia é a base presente e mantendo-se em todos os momentos subsequentes, o conceito imanente em suas determinações ulteriores. Assinalemos, ainda, 
que Hegel insiste na acepção de conservação da Aufhebung, no processo mesmo de dissolução das determinações lógicas. O percurso lógico é aquele que se conserva. O começo é o ser em seu desenvolvimento lógico.

Do fato de que o resultado constitui também o fundamento, em uma etapa superior de concretização. O fundamento, tornando-se efetividade, o progredir deste saber, que é a filosofia, não é algo arbitrário, provisório, nem algo problemático e hipotético, mas determinado pela natureza da coisa e do próprio conteúdo. Trata-se de uma articulação necessária de categorias, umas produzindo-se nas outras. Cabe à filosofia apresentar-se a si mesma, entendendo essa apresentação como uma forma de demonstração, um provar esse começo como o verdadeiro ponto de partida. A pergunta pelo começo se insere no interior do Saber absoluto que se indaga pelo ser e por sua própria unidade conquistada, compreendida como uma espécie de rememoração lógica de seu percurso figurativo. O "saber puro" volta, desse modo, a si mesmo. As determinações lógicas, no dizer do próprio Hegel em suas anotações, estavam, por assim dizer, atrás da consciência. Para chegar, no entanto, à sua ordenação lógica, torna-se necessário um novo tipo de saber, o da sabedoria da lógica. Ou seja, o resultado do processo fenomenológico reside no começo da ciência pura, que nos oferece uma noção depurada de ser, o que se vai tornar essência e, posteriormente, ideia.

A filosofia é a apresentação da coisa mesma. No começo, o ser pode se lhe apresentar como uma palavra vazia, mas nisso consiste precisamente o trabalho da ciência, o de expor as determinações lógicas aí contidas. Mais especificamente, o conceito ele mesmo aparece sob esse nome, isto é, o ser vai revelar-se como conceito, tornando-se ele mesmo o conteúdo do saber que assim se sabe, torna-se o seu próprio objeto. O aparecer do ser se dará mediante a apresentação de suas categorias lógicas. Trata-se da unidade mais pura, a do ato de conhecer e a do que é conhecido. O ser é portador do seu processo lógico de constituição. A filosofia, ao pensar-se, expõe o ser em suas determinações, o ser como começo, o ser como conceito. 
Neste sentido, o começo da Ciência absoluta, da Filosofia primeira, deve ser ele mesmo um começo absoluto, nada podendo pressupor, senão aquilo que ele se dá como determinação-de-pensamento, como categoria, como resultado do seu processo de constituição de si. Ele só tem a si mesmo como seu próprio começo, como seu próprio conceito. Com efeito, o começo não deve ser mediado por nada extrínseco a si. Ele deve, na verdade, ser o fundamento de todo conhecimento. Do mesmo modo, ele não pode ter determinação alguma em relação à outra coisa. $\mathrm{O}$ começo é, então, o ser puro. Mais particularmente, a filosofia hegeliana via o uso propriamente ontológico que faz do verbo setzen, pôr, toma algo sempre do ponto de vista do seu processo de reposição, este conferindo a noção própria de ser. Ela parte do processo através do qual algo é posto e reposto por seu próprio processo. $\mathrm{Ou}$ seja, graças ao uso que faz do verbo setzen, pôr, Hegel procura se colocar na posição de pensar o ser em sua mediação categorial, não sensível. O uso do verbo ser, em sua função existencial, torna-se, para ele, por demais marcado por significar uma forma de existência empírica, sensível, que impediria, precisamente, a mediação do conceito por ele visado.

O absoluto adquire, assim, uma nova posição, pois ele vem a ser concebido como o ser em seu processo de mediação, ser que já fez em si a experiência e a superação da dualidade entre o sujeito e o objeto. Logo, a questão do começo deve ser colocada como a da imediatez mediada, não a da imediatez sensível ou empírica. Conforme vimos, o começo consiste no ser puro, no Saber absoluto, tal como veio a ser na Fenomenologia do Espírito. Um ser portador de todo o seu processo, da imediação que o produziu, um ser que traz em si a estrutura de ser. Estrutura essa representada pelas categorias, expressão lógica do vir a ser, denominadas por Hegel de determinações-do-pensamento. O pensamento confrontado consigo mesmo vai expor a sua estrutura lógica. $\mathrm{Ou}$ ainda, a "ciência", na acepção hegeliana, não é um conhecimento fragmentário do real, mas a totalidade dele. $\mathrm{O}$ começo não pode depender de algo outro, extrínseco. O pensamento em seu exercício filosófico não pode ter nenhum conteúdo (perceptível), pois 
teríamos, aqui, uma diferenciação não mediada, uma relação de exterioridade.

O espírito que se liberou da dualidade entre o subjetivo e o objetivo, que já fez a experiência fenomenológica da consciência em seu processo de purificação de si, tem como começo o ser livre e puro. Hegel faz, portanto, intervir um pressuposto de novo tipo, o que é proveniente do conceito de saber, o que se concretizou no Saber absoluto. A pressuposição não pode ser aquela proveniente de algo externo, pois criar-se-iam laços de dependência, configurando uma pressuposição heterônoma, não-livre. Nesse sentido, o uso feito do conceito de liberdade remete à liberação da oposição entre o subjetivo e o objetivo, de maneira que o pensamento esteja em condições de se dar suas próprias determinações.

Tal formulação implica que Hegel reconsidere a questão do ser à luz da predicação. O problema central para ele consiste, inclusive na Fenomenologia do Espírito, no modo mesmo mediante o qual algo é dito ser, ou ainda, no modo através do qual o conceito de existência é atribuído a conceitos. Mesmo na consciência sensível da Fenomenologia do Espírito, não estamos diante de uma consciência empírica, mas da forma graças à qual a consciência se conduz em seu processo de se dizer mundo, de dizer que algo é. O problema do ser torna-se o problema da atribuição de ser numa perspectiva que é a da própria existência.

Na Enciclopédia, essa questão do ser puro constituindo-se como começo se coloca como a do imediato mais simples que é o próprio pensamento defrontando-se consigo. Depreende-se, então, a identificação do ser puro ao absoluto. Sob uma imagem representativa, podemos chamar o absoluto de Deus. Não interessa evidentemente aqui a história das religiões, que seria somente um histórico de suas formas representativas. As questões históricas desaparecem diante do conceito de absoluto. O próprio Deus é considerado como Inbegriff, um conceito englobante de toda a realidade, aquilo que Hegel denominará propriamente de Ideia, ou ainda, Deus é o ser em todo ser-aí. Sob essa ótica, a questão será a de como se pode atribuir existência a Deus ou ao absoluto. Impõe-se a distinção entre a atribuição da existência e a pressu- 
posição de existência sob a forma empírica de objetos dados, que são simplesmente admitidos como presentes. A existência se confunde aqui a algo com o qual a consciência se defronta.

Em termos filosóficos, estamos diante de uma questão metafísica por excelência, a que é conhecida como a da prova da existência de Deus, a da atribuição de existência ao absoluto, ou melhor, ao seu conceito. Ressaltemos, en passant, que, em Santo Anselmo, por exemplo, não há propriamente dito uma prova da existência de Deus, pois a sua existência não é em nenhum momento questionada. Ela tem, de certa forma, o estatuto de algo dado, exterior ao pensamento, de tal maneira que esse deve nela reconhecer-se. Nesse sentido, pode-se dizer que o pensamento se reconhece em um Deus que lhe é exteriormente oferecido. É o espaço mesmo da interlocução, de fundo religioso, que limita o alcance da proposição filosófica. Deus funciona como uma espécie de realidade dada, anterior ao pensamento. Este, por sua vez, é posterior ao ato do comparecimento existencial de Deus.

Ora, essa posição se inverte na filosofia cartesiana, na medida em que essa parte, precisamente da dúvida radical concernente à existência de Deus, o pensamento defronta-se apenas consigo mesmo, sem nenhum ponto de apoio externo, muito menos religioso que lhe forneceria uma baliza para as suas interrogações. A própria palavra Deus desaparece em proveito das ideias de perfeição e de infinitude que, elas sim, tornam-se objeto de prova. Deus se torna um conceito que deve ser provado, um conceito trazido ao interior do pensamento. A prova vai, portanto, consistir numa atribuição de existência às ideias de perfeição e de infinitude, numa operação que relaciona ideias com ideias, sem nenhuma referência exterior a esse ato filosófico de ilação de conceitos. Isto é, existência de realidade dada se torna um conceito, algo que deve ser atribuído, uma forma de atribuição. O empírico desaparece em proveito do que podemos chamar de uma existência categorial ou noética.

O saber se relaciona consigo mesmo quando se defronta com as categorias, que são as suas formas próprias de operação. O ser vai, nesse sentido, remeter ao seu vir a ser, o que significa o 
seu processo de negação de si, o seu cessar de ser na perspectiva do seu próprio devir. Pensar o ser implica pensar a negação do ser, o nada, como se oferecendo, por este mesmo movimento, ao saber. A pergunta pelo começo pode igualmente comportar a pergunta pelo nada, mas não a do nada vazio, do qual nada provém, mas o nada que se faz conjuntamente ao ser, o não-ser do ser, que vai repor uma unidade de novo tipo. O começo não é o nada puro, mas algo que deve surgir desse processo de dissolução. Ora, o próprio saber puro é ele também originário de um processo de negação, de um processo de dissolução, uma dissolução criadora que o tornou possível e marca, dessa maneira, o seu próprio desdobramento posterior. Numa perspectiva cartesiana, que será retomada por Hegel sob uma outra forma, o ser já está presente no próprio ato de negar do pensamento: "Se eu nego a existência de todas as coisas, não posso negar que estou negando". O começo contém um e outro, o ser e o nada, o pensamento defrontando-se com o ser e com o nada.

Numa visão unilateral do começo, o ser e o nada estariam dados como diferentes, porque o começo enviaria a algo de outro. Ele seria um não-ser que se relaciona com o ser como com um outro, pois, na verdade, ele vai ser somente quando rumar ao ser. Mas é, precisamente, esse processo do ser ao não-ser e deste naquele que vai consistir inicialmente no próprio conteúdo do saber, se é a que palavra conteúdo está aqui propriamente utilizada. Aliás, tanto o conceito de ser quanto o de nada, em suas apresentações, recorrem ao conceito de ser, que Hegel toma em sua acepção de predicação enquanto preliminar à atribuição de ser e de existência, embora essa existência seja ela, por sua vez, resultante desse processo de negação. Logo, o começo não é o nada puro, mas o ser que em sua negação, no nada, faz surgir uma nova categoria. O ser está já contido no nada, na negação de ser. O começo, neste sentido, contém um e outro, o ser e o nada, o ser que é, ao mesmo tempo, não-ser. Ou seja, um termo é engendrado pelo outro. Não há, hegelianamente falando, o vir-a-ser do ser que não passe pela sua negação. 
Caberia assinalar que os dois primeiros momentos, ser e nada, que, na verdade, só se concretizam no devir ${ }^{6}$, onde começarão as transições dialéticas propriamente ditas, possuem a especificidade de remeterem as condições mesmas que fazem com que o dizer seja possível. Ser, nada, afirmação, negação, mas também, e esta é sua especificidade hegeliana, transição de um a outro, são as condições mesmas graças às quais dizemos que algo seja ou exista, o que coloca a questão que dizer o ser (e o nada) já é um dizer desde sempre inscrito no ser que ele quer dizer. $\mathrm{O}$ dizer lógico deverá interiorizar-se em si mesmo, no devir, a partir de suas próprias condições de ser, via manejo da cópula e de sua negação. Nesse sentido, pode-se dizer, Hegel parte aqui do uso natural da linguagem, porém um uso natural já portador de todo o seu percurso fenomenológico de constituição, que deve, agora, ser purificado pelas categorias, que, nele, se encontram atuantes.

A explicitação das categorias da linguagem, desde as noções de ser e nada e dos usos da cópula e de sua negação, até a Idéia absoluta, passando pelas essencialidades, constituem o objeto próprio da Lógica, em que esta se torna o seu próprio objeto, ela mesma, o Si-mesmo. Assinalemos, ainda, que não se trata somente de uma explicitação das categorias presentes na linguagem, mas de uma explicitação lógica, aquela que tem no Saber absoluto, o saber de si, o saber puro, o seu ponto de partida. Ou seja, Hegel, ao empreender o percurso lógico, já se encontra "preso", por assim dizer, neste mesmo percurso, pois a sua exposição consiste na apresentação da linguagem, das categorias, tais como essas se apresentaram logicamente na Fenomenologia do Espírito, entendida como o percurso mesmo da consciência em seu uso imediato da linguagem através de sua própria formação cultural. O saber já se constituiu na realidade. A Lógica, sob essa ótica, trata da apresentação dessa linguagem ciente de si mesma, uma ciência da linguagem, uma ciência da lógica, nesse sentido, uma metafísica pós-kantiana. Uma metafísica baseada no processo de

\footnotetext{
6 Gadamer, Hans-Georg. Hegels Dialektik. Tübingen, J. C. B. Mohr, 1971, cap. IV. 214 - Universidade Católica de Pernambuco
} 
autodissolução das categorias num movimento interno à linguagem, ao saber, operando dentro de si mesmo e independente de toda objetivação mundana, a que se daria no mundo externo dos objetos. Objetivação, para Hegel, significa a própria objetivação do discurso em si mesma, da linguagem, da lógica, logo, do saber.

A análise do começo daria o conceito da unidade do ser e do não-ser. De uma forma refletida, a unidade do ser diferente e do não-ser diferente, ambos se determinando reciprocamente. Isso vai implicar a consideração de que tal unidade é de tipo sintético, expondo uma relação necessária entre conceitos, que se opõem mutuamente. Ou seja, a filosofia vai expor como se faz esse processo categorial, não procedendo por definições, pois esse procedimento seria próprio das ciências que estudam setores da realidade, não se preocupando com sua unidade subjacente, a que engloba o conjunto de suas determinações. Trata-se de um mostrar, de um apresentar, porque a filosofia não pode proceder por definições, sendo ela objeto de si mesma. Ela é, assim, a sua própria forma de apresentação, à qual Hegel procura conferir na Fenomenologia do Espírito um contorno figurativo e, na Ciência da Lógica, lógico.

O ser, em Hegel, vai remeter ao vir-a-ser, ao seu movimento negativo de constituição e, por intermédio dele, ao que considera como o movimento da essência, o movimento da reflexão propriamente falando. A essência é o movimento do ser em sua interioridade, o processo reflexivo que o constitui. $O$ ser não é diferente da essência, porque esta é o próprio movimento do ser. Quando o ser vem a ser na esfera de sua imediatidade, ele torna-se conceito. O ser, abstratamente considerado, seria apenas uma forma carente de determinações que, uma vez desenvolvidas, se apresentarão sob a forma da ideia.

A questão do absoluto, na verdade a questão do acesso ao absoluto, só é corretamente formulada se for acoplada, elaborada, a partir da questão do começo, pois o que importa é o percurso mesmo da demonstração. O ponto de partida em seu desdobramento, em seu desenvolvimento, vai remeter à conclusão de um périplo filosófico em que o absoluto se finitizará categorialmen- 
te, ganhando infinitude, ou seja, autodeterminando-se ${ }^{7}$. Qualquer abreviação de acesso ao absoluto, como a que se apresentaria sob a forma de uma intuição intelectual, é considerada, por Hegel, como não científica ao fazer a economia de sua prova, de seu método, de seu processo. Não há atalho possível no que diz respeito à necessidade da mediação que é o trabalho próprio da filosofia. A mediação consiste em um processo que parte de um algo portador de um desenvolvimento possível, que reside em uma apresentação de conceitos segundo um rigor lógico, por mais difícil que consista em determinar cada uma dessas etapas. Tal processo não pode ser arbitrário ou assertórico. Não há relação direta com o absoluto, visto que o saber reside em sua exposição. Assim, o começo, a partir de uma determinação, reside na progressão a uma outra. Se, então, na expressão do absoluto, do eterno, de Deus em sua intuição ou em seus pensamentos, há mais do que no ser puro, este algo a mais, se existente, deverá adotar a forma de um movimento de categorias, que é o percurso mesmo da Ciência da Lógica. Surge como determinação primeira o ser, que não é a representação do divino, mas o ser-aí interno ao próprio saber.

MacTaggart, op. cit., p. 27.

216 - Universidade Católica de Pernambuco 